\title{
Simultaneous increase of Cryptosporidium infections in the Netherlands, the United Kingdom and Germany in late summer season, 2012
}

\author{
N Fournet ${ }^{1,2,3}$, M P Deege ${ }^{3,4,5}$, A T Urbanus ${ }^{1}$, G Nichols ${ }^{6}$, B M Rosner 7 , R M Chalmers ${ }^{8}$, R Gorton ${ }^{9}$, K G Pollock ${ }^{10}$, J W B van der \\ Giessen ${ }^{1}$, P C Wever ${ }^{11}$, J W Dorigo-Zetsma ${ }^{12}$, B Mulder ${ }^{13}$, T G Mank ${ }^{14}$, I Overdevest ${ }^{15}$, J G Kusters ${ }^{5}$, W van Pelt ${ }^{1}$, \\ L M Kortbeek (Titia.Kortbeek@rivm.nl) \\ 1. Centre for Infectious Diseases Control, National Institute for Public Health and the Environment (RIVM), Bilthoven, the \\ Netherlands \\ 2. European Programme for Intervention Epidemiology Training (EPIET), European Centre for Disease Prevention and Control \\ (ECDC), Stockholm, Sweden \\ 3. These authors contributed equally to this work \\ 4. Saltro Diagnostic Centre, Utrecht, the Netherlands \\ 5. Department of Medical Microbiology, University Medical Centre Utrecht, Utrecht, the Netherlands \\ 6. Gastrointestinal, Emerging and Zoonotic Infections Department, Health Protection Agency Colindale, London, United \\ Kingdom \\ 7. Department for Infectious Disease Epidemiology, Robert Koch Institute (RKI), Berlin, Germany \\ 8. Cryptosporidium Reference Unit, Public Health Wales, Swansea, United Kingdom \\ 9. Health Protection Agency, North East Region, Newcastle, United Kingdom \\ 10. Health Protection Scotland, Glasgow, United Kingdom \\ 11. Department of Medical Microbiology and Infection Control, Jeroen Bosch Hospital, 's-Hertogenbosch, the Netherlands \\ 12. Central Laboratory for Bacteriology and Serology, Tergooi ziekenhuizen, Hilversum/Almere, the Netherlands \\ 13. Laboratory of Medical Microbiology and Public Health, Enschede, the Netherlands \\ 14. Regional Laboratory for Medical Microbiology and Public Health, Haarlem, the Netherlands \\ 15. Laboratory for Medical Microbiology and Immunology, St Elisabeth Hospital, Tilburg, the Netherlands
}

\section{Citation style for this article}

Fournet N, Deege MP, Urbanus AT, Nichols G, Rosner BM, Chalmers RM, Gorton R, Pollock KG, van der Giessen JW, Wever PC, Dorigo-Zetsma JW, Mulder B, Mank TG, Overdevest I, Kusters JG, van Pelt W, Kortbeek LM. Simultaneous increase of Cryptosporidium infections in the Netherlands, the United Kingdom and Germany in late summer season, 2012. Euro Surveill. 2013;18(2):pii=20348. Available online: http://www.eurosurveillance.org/ViewArticle.aspx?Articleld=20348

Starting August 2012, an increase in Cryptosporidium infections was reported in the Netherlands, the United Kingdom and Germany. It represented a 1.8 to 4.9-fold increase compared to previous years. Most samples were $C$. hominis IbA10G2. A case-control study was performed in the Netherlands but did not identify an endemic source. A case-case study in the north of England found travel abroad to be the most common risk factor.

In August 2012, an unprecedented increase of Cryptosporidium infections, as detected through analysis of faecal samples from patients with gastrointestinal complaints, was independently reported to the regional public health services, and subsequently to the National Institute for Public Health and the Environment (RIVM) by several microbiology laboratories throughout the Netherlands. In the same time period, Germany and parts of the United Kingdom (UK), specifically England, Wales and Scotland, but not Northern Ireland, also identified an unexpected excess of cryptosporidiosis cases compared to former years. Most samples in the UK and the Netherlands were $C$. hominis IbA10G2. No other European countries reported an increase of Cryptosporidium infections. Finland reported two ongoing outbreaks caused by C. parvum.
In the Netherlands, Cryptosporidium infection is not a notifiable disease, therefore there are no solid data on the incidence of human infections. In the UK, surveillance of Cryptosporidium was implemented in the 1990s. Positive results from laboratory testing are now notifiable. In Germany, C. parvum infection has been notifiable since 2001, but is mostly reported without species determination.

The increased number of cryptosporidiosis infections in three EU countries in the same period of time is unusual and is a great public health concern. In this paper, we present microbiological and epidemiological investigations of this increase in those three countries.

\section{Background}

Cryptosporidiosis is a disease caused by the parasite Cryptosporidium. The main symptoms in humans are watery diarrhoea, nausea, vomiting, low-grade fever and abdominal pain lasting from a few days to a few weeks. In immunocompromised people such as AIDS patients, the infection can be severe and may result in significant morbidity and mortality [1]. The two predominant species associated with human disease are Cryptosporidium hominis, affecting only humans, and C. parvum, affecting both humans and animals [2]. The principal reservoirs are humans, cattle and other domestic animals. The oocysts, containing sporozoites 
(the infectious form of this parasite) are excreted in the host's faeces. They are transmitted by the faecaloral route, via person-to-person or animal-to-person spread, or through the ingestion of contaminated water and food.

\section{Methods}

\section{Microbiological investigations}

Cryptosporidium was detected by medical microbiology laboratories in the Netherlands using standard routine detection methods (microscopy using modified Ziehl Neelsen staining or enzyme immunoassay and/or multiplex P(R). A selection of the positive samples was sent to the RIVM for further investigation and subtyping using gp6o amplification sequencing. In England and Wales cases were diagnosed in local microbiology laboratories using auramine or modified Ziehl Neelsen staining or enzyme immunoassay, and samples were sent to the Cryptosporidium Reference Unit in Swansea for speciation by real-time PCR and subtyping using gp6o sequencing. In Germany, Cryptosporidium was detected by diagnostic laboratories using enzyme immunoassay or microscopy.

\section{Epidemiological investigations}

\section{of cases in the Netherlands}

Data of Cryptosporidium-positive cases detected by faecal testing since 2010 were requested from nine large routine microbiology laboratories spread throughout the Netherlands (together servicing approximately $21 \%$ of the Dutch population).

In addition, a case-control survey was conducted in four regions. A case was defined as a person who became ill with diarrhoeal symptoms after 1 August 2012 with a stool sample positive for Cryptosporidium. Public health services interviewed cases by telephone or posted the questionnaire. Collected data included date of birth, sex, symptoms (profuse and watery diarrhoea), date of onset, and possible sources of infection and exposures in the 10 days prior to onset of symptoms. Controls were randomly selected from a register of residents of 322 Dutch municipalities and were matched by sex and year of birth. The same questionnaire as for cases was send to 316 controls. Univariable and multivariable logistic regression analyses were performed, adjusted by sex and age group.

\section{Epidemiological investigations}

\section{in the United Kingdom}

To examine the descriptive epidemiology of the increase noted from mid-August 2012, Cryptosporidium cases reported to national surveillance were compared to those reported over the previous years. A case-case study in the north-east compared risk factors ascertained through routine interviews of cryptosporidiosis cases in weeks 32 to 42 of 2012 with the previous three years.
Epidemiological investigations in Germany Cryptosporidium cases (without species determination) reported to national surveillance were compared to those reported in the previous years.

\section{International investigation}

The RIVM sent out an urgent inquiry on 25 October 2012 on the Epidemic Intelligence Information System for Food and Waterborne Diseases (EPIS-FWD managed by the European Centre for Disease Prevention and Control (ECDC)) to inform other European Union (EU) Members States of this increase.

\section{Results}

\section{The Netherlands}

The number of Cryptosporidium cases from 2010 was readily available for eight laboratories that had had no change in diagnostic procedures since then. For weeks 31 to 42 , they reported 524 positive samples for Cryptosporidium in 2012 compared with 115 in 2010 and 98 in 2011 (Figure). A peak with 292 Cryptosporidium cases occurred in weeks 35 to 38 of 2012, seven times higher than in the same period in 2010 and 2011 (42 and 45 cases, respectively). From weeks 31 to 42 in 2012, $58 \%$ of Cryptosporidium infections were diagnosed in children under the age of 10 years (comparable to $58 \%$ in 2010 and $45 \%$ in 2011), and $58 \%$ of these children were male. Seventy-two per cent of cases 15 years and older were female. The sex distribution was similar as in the two previous years, but the age distribution was significantly different ( $p<0.0001)$. Preliminary data showed 80 of 95 stool samples typed contained C. hominis, of which 78 belonged to the dominant gp6o subtype IbA10G2; the remaining 15 samples contained C. parvum with six different subtypes.

The Dutch case-control survey included 82 cases and 125 controls. More cases (36\%) than controls (22\%) had travelled abroad, mostly in Europe $(p=0.03)$. The most visited countries were France (seven controls and nine cases) and Spain (two controls and nine cases). Seventy per cent of the cases and $66 \%$ of the controls had contact with surface water (in a swimming pool, sea, river or lake) in the 10 days before onset of symptoms $(p=0.56)$. Contact with farm animals was not significantly different between cases and controls (33\% vs. $40 \%, p=0.30)$. More controls than cases drank tap water on a daily basis ( $78 \%$ vs. $67 \%, p=0.07)$. In the multivariable logistic regression analysis adjusted for sex and age group, only drinking bottled mineral water remained associated with Cryptosporidium infection (odds ratio: 2.72 ; 95\% confidence interval: 1.10-6.76; $p=0.03$ ), although only $21 \%$ of cases had drunk mineral water compared to $11 \%$ of controls.

\section{The United Kingdom}

In the UK, there was a two-fold increase in laboratoryconfirmed Cryptosporidium cases, with 3,230 cases (weeks 33-46) compared to an average of 1,641 cases reported for the same weeks in the previous two years, 
Cryptosporidium cases reported from eight laboratories in the Netherlands and cases notified in Germany and the United Kingdom, January 2010-November 2012
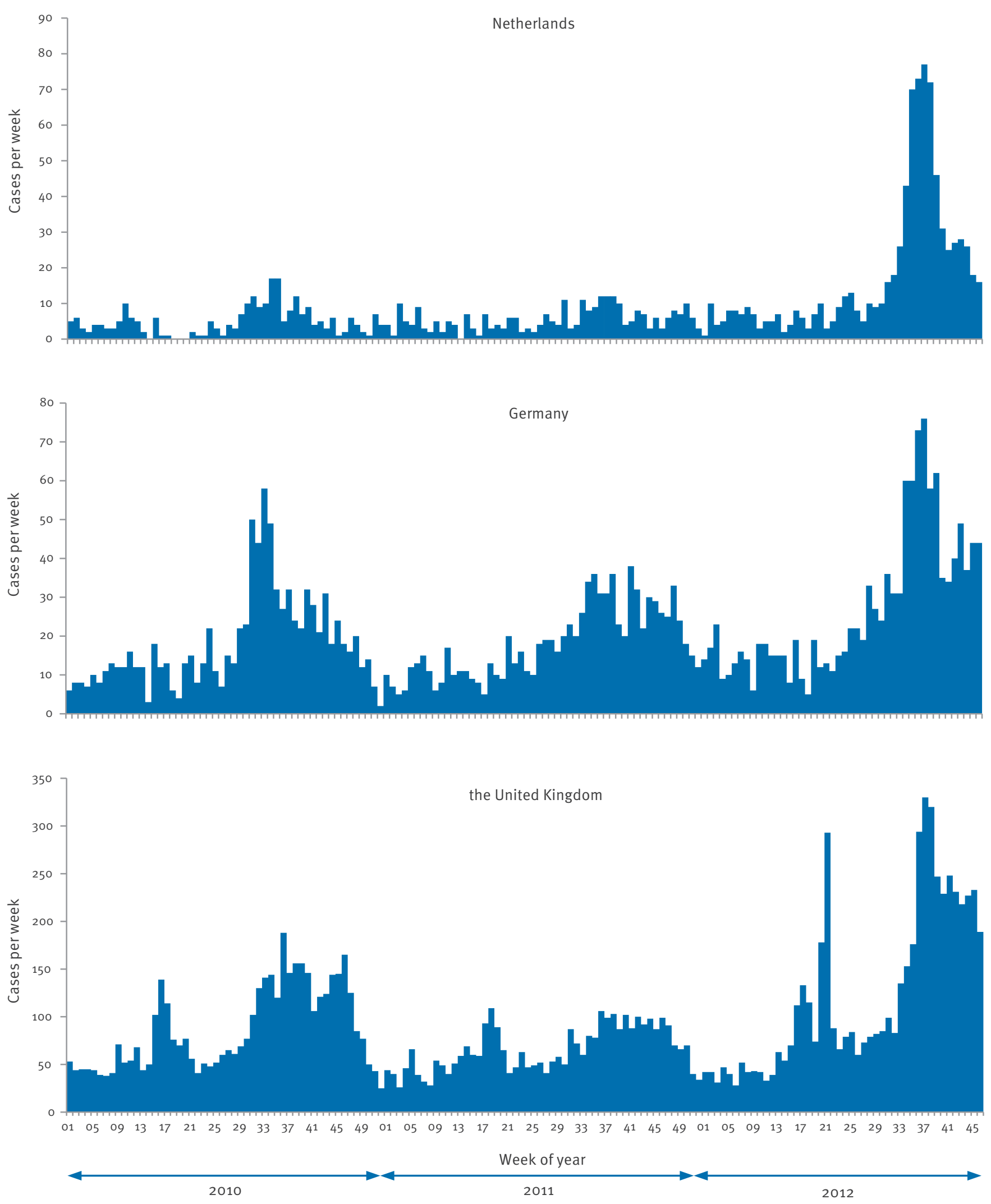
(2,002 cases in 2010 and 1,279 in 2011) (Figure). The percentage of cases over 20 years of age was significantly increased over that seen in the previous two years for weeks 33 to 46 , but there was no significant change in age distribution.

Of 2,115 typed samples from weeks 33 to 48 inclusive, 1,577 (75\%) contained C. hominis, 497 (23\%) C. parvum and 45 (2\%) contained other species/genotypes or were not typable. Gp6o subtyping was undertaken on 48 not travel-related $C$. hominis cases from weeks 33, 35 and 37 in the age group with most cases, the 5-19 yearolds; of those, 37 ( $77 \%$ ) were subtype IbA10G2, five belonged to two other types, and six did not amplify in the PCR. Almost a third of all specimens received at the Cryptosporidium Reference Unit and collected in weeks 33 to 37 were reported as travel-related, a proportion that declined after week 37 and from week 42 onwards was $110 \%$ of cases, which is in line with what has been seen in previous years. Spain and Turkey were the most frequently visited countries.

A case-case study in the north-east of England compared risk factors for weeks 32 to 42 in 2012 with the years 2009 to 2011. Travel abroad was reported in 54\% of cases; this proportion had been similar in the previous years but the total case number was 2.2-fold higher. Of the countries visited, Spain and Turkey were most common. Among the cases not related to travel abroad there were significant positive associations with eating at a restaurant (32\% in 2012 vs. $4 \%$ in $2009-2011$, $\mathrm{p}=0.001)$ and dog ownership (46\% in 2012 vs. $25 \%$ in 2009-2011, $p=0.02$ ). The difference in consumption of bottled water was not statistically significant ( $11 \%$ vs. $10 \%$ in $2009-2011, p=0.44$ ), and swimming pool use was significantly less common in 2012 than between 2009 and 2011 (18\% vs. 37\%, p=0.02).

\section{Germany}

In Germany, there was a 1.8-fold increase of notified cryptosporidiosis cases in weeks 34 to 44 with 584 cases (Figure), compared to 316 cases in 2010 and 333 cases in 2011 in the same period. A peak occurred in week 37 with 76 cases ( 32 in 2010 and 31 in 2011 in the same week). The median age of cases notified in this time period was 19 years, and 50\% of cases were male, similar to the two previous years. Laboratory diagnostic procedures did not include typing.

\section{International investigation}

The EPIS alert from the Netherlands identified increases in the UK and Germany. No increase in cryptosporidiosis was reported in Denmark, France, Hungary, Ireland, Lithuania, Malta and Norway. Finland reported two ongoing outbreaks caused by C. parvum.

\section{Discussion}

An increase in the number of Cryptosporidium cases was observed from August 2012 throughout the Netherlands, all regions of England, Wales, Scotland and also Germany. In the Netherlands, the increase lasted from week 31 to 42 while in the UK, the excess cases were reported from week 33 to 46 and in Germany from week 33 to 44 . In the Netherlands and the UK, the most frequently isolated species was $C$. hominis gp6o subtype IbA10G2, which is the dominant subtype in these countries $[3,4]$.

Cryptosporidium outbreaks have been associated with contaminated drinking water or recreational water $[2,5,6]$, contact with farm animals [7], person-to-person spread in daycare and other institutions [8], food handling [9], or consumption of unpasteurised apple juice [10], milk, fruits or vegetables $[11,12]$. In the Netherlands, the few published outbreaks have been caused by C. parvum [13], while multiple outbreaks in the UK have involved both $C$. parvum and $C$. hominis [14].

In the Netherlands, the heavy rainfall in July and August 2012, followed by an extremely warm period with temperatures up to $35^{\circ} \mathrm{C}$ at the end of August, suggested the potential for contamination of surface water $[15,16]$. The case-control study did not show an association with surface water contact or tap water consumption. However, this risk factor cannot be excluded entirely because the statistical non-significance could be due to a lack of power. Almost $70 \%$ of controls and cases reported bathing in surface water in this warm summer holiday period. Travelling abroad before the onset of symptoms was significantly different between cases and controls, but this association did not remain in the multivariate analysis. Drinking bottled mineral water was associated with cryptosporidiosis, but only $21 \%$ of cases and $11 \%$ of the controls reported daily mineral water consumption. Further questionnaires were administered to cases who drank bottled mineral water, but no particular brand has emerged.

During the period when questionnaires were sent out to Dutch cases and controls, there was also a Salmonella Thompson outbreak in the Netherlands [17]. However, there was no significant increase in the number of referred faecal samples, and the increased Cryptosporidium cases are unlikely to result from such screening bias.

In the UK, travel abroad was an important risk. However, the percentage of travel-related cases was similar to the previous years and cannot explain all cryptosporidiosis cases. The association with eating out suggests the possibility that transmission of infection in some cases might have been through consumption of contaminated food or drinks.

Because the number of Cryptosporidium-positive samples in the Netherlands, the UK and Germany increased during the same period, common exposures or influencing factors might be expected. However, no single source has been found that could explain the increase of cryptosporidiosis seen in these countries. Foreign travel has been an important risk in the UK and 
bottled mineral water raised as a hypothesis in the Netherlands. However, plausible factors might include multiple sources, extreme weather conditions, personto-person transmission and other, still unidentified risk factors. Alternatively, the increase in different countries may have developed independently which could explain the difference in age distribution compared to previous years in the Netherlands but not in the UK and Germany. This increase in cryptosporidiosis across a wider geographic area highlights the need for wider surveillance, development of better subtyping methods, the inadequacy of controls for travel-related infections and a need for further work on bottled waters [18] and foods as potential Cryptosporidium risks.

\section{Acknowledgments}

We would like to thank the patients and controls, the people working at the Dutch Municipal Health Services (GGD Flevoland, GGD Gooi en Vechtstreek, GGD Utrecht, GGD Kennemerland, GGD Twente, GGD Zuid-Limburg, GGD Hart voor Brabant) for their extra efforts and help in the investigation, the laboratories for sending in their data and the samples for molecular typing to RIVM. Especially, we like to thank Rody Zuidema, Ciska Schets, Corien Swaan, Jeroen Roelfsema, Sietze Brandes and Hein Sprong (all Center for Infectious Disease Control, RIVM) for their assistance in all phases of the increase. Thanks also to Sebastiaan Voskuil (University Medical Centre Utrecht), Sjoerd Peeters (Saltro Diagnostic Centre), Jo Lawrence, Bob Adak, Isabel Oliver, Gayle Dolan and Stephen Morton (all HPA) and the staff of the Cryptosporidium Reference Unit.
References

1. Hunter PR, Nichols G. Epidemiology and clinical features of Cryptosporidium infection in immunocompromised patients. Clin Microbiol Rev. 2002;15(1):145-54.

2. Leitch GJ, He Q. Cryptosporidiosis-an overview. J Biomed Res. 2012;25(1):1-16.

3. Wielinga PR, de Vries A, van der Goot TH, Mank T, Mars $\mathrm{MH}$, Kortbeek LM, et al. Molecular epidemiology of Cryptosporidium in humans and cattle in The Netherlands. Int J Parasitol. 2008;38(7):809-17.

4. Chalmers RM, Hadfield SJ, Jackson CJ, Elwin K, Xiao L, Hunter P. Geographic linkage and variation in Cryptosporidium hominis. Emerg Infect Dis. 2008;14(3):496-8.

5. Semenza JC, Nichols G. Cryptosporidiosis surveillance and water-borne outbreaks in Europe. Euro Surveill. 2007;12(5): pii=711. Available from: http://www.eurosurveillance.org/ ViewArticle.aspx?Articleld $=711$

6. Insulander M, Lebbad M, Stenstrom TA, Svenungsson B. An outbreak of cryptosporidiosis associated with exposure to swimming pool water. Scand J Infect Dis. 2005;37(5):354-60.

7. Smith RP, Chalmers RM, Mueller-Doblies D, Clifton-Hadley FA, Elwin K, Watkins J, et al. Investigation of farms linked to human patients with cryptosporidiosis in England and Wales. Prev Vet Med. 2010;94(1-2):9-17.

8. Artieda J, Basterrechea M, Arriola L, Yague M, Albisua E, Arostegui N, et al. Outbreak of cryptosporidiosis in a child day-care centre in Gipuzkoa, Spain, October to December 2011. Euro Surveill. 2012;17(5):pii=20070. Available from: http:// www.eurosurveillance.org/ViewArticle.aspx?Articleld $=20070$

9. Quiroz ES, Bern C, MacArthur JR, Xiao L, Fletcher M, Arrowood MJ, et al. An outbreak of cryptosporidiosis linked to a foodhandler. J Infect Dis. 2000;181(2):695-700.

10. Blackburn BG, Mazurek JM, Hlavsa M, Park J, Tillapaw M, Parrish M, et al. Cryptosporidiosis associated with ozonated apple cider. Emerg Infect Dis. 2006;12(4):684-6.

11. Robertson LJ, Chalmers RM. Foodborne cryptosporidiosis: is there really more in Nordic countries? Trends Parasitol. 2013;29(1):3-9.

12. Gherasim A, Lebbad M, Insulander M, Decraene V, Kling A, Hjertqvist $M$, et al. Two geographically separated food-borne outbreaks in Sweden linked by an unusual Cryptosporidium parvum subtype, October 2010. Euro Surveill. 2012;17(46):pii=20318. Available from: http://www. eurosurveillance.org/ViewArticle.aspx?Articleld=20318

13. Yap KB, van der Giessen JW, Brimicombe RW. Cryptosporidium na een bezoek aan de kinderboerderij. [Cryptosporidium after visiting the petting z0o]. Infectieziekten Bulletin. 2003;14:3625. Dutch. Available from: http://www.rivm.nl/dsresource?type =pdf\&objectid=rivmp:59289\&versionid=\&subobjectname=

14. Chalmers RM, Elwin K, Thomas AL, Guy EC, Mason B. Long-term Cryptosporidium typing reveals the aetiology and speciesspecific epidemiology of human cryptosporidiosis in England and Wales, 2000 to 2003. Euro Surveill. 2009;14(2):pii=19086. Available from: http://www.eurosurveillance.org/ViewArticle. aspx?Articleld $=19086$

15. Schets FM, Italiaander R, van den Berg HH, de Roda Husman AM. Rainwater harvesting: quality assessment and utilization in The Netherlands. J Water Health. 2010;8(2):224-35.

16. Schets FM, van Wijnen JH, Schijven JF, Schoon H, de Roda Husman AM. Monitoring of waterborne pathogens in surface waters in amsterdam, the Netherlands, and the potential health risk associated with exposure to cryptosporidium and giardia in these waters. Appl Environ Microbiol. 2008;74(7):2069-78.

17. Friesema IH, de Jong $A E$, Fitz James IA, Heck ME, van den Kerkhof JH, Notermans DW, et al. Outbreak of Salmonella Thompson in the Netherlands since July 2012. Euro Surveill. 2012;17(43): pii=20303. Available from: http://www. eurosurveillance.org/ViewArticle. aspx?Articleld $=20303$

18. Nichols RA, Campbell BM, Smith HV. Identification of Cryptosporidium spp. oocysts in United Kingdom noncarbonated natural mineral waters and drinking waters by using a modified nested PCR-restriction fragment length polymorphism assay. Appl Environ Microbiol. 2003;69(7):4183-9. 